\title{
Efficacy and Safety of Novel Oral Anticoagulants for Atrial Fibrillation Ablation: An Updated Meta-Analysis
}

\author{
Ajay Vallakati · Abhishek Sharma · Mohammed Madmani · Madhu Reddy • \\ Arun Kanmanthareddy · Sampath Gunda • Dhanunjaya Lakkireddy • \\ William R. Lewis
}

Received: March 14, 2016 / Published online: April 22, 2016

(c) The Author(s) 2016. This article is published with open access at Springerlink.com

\section{ABSTRACT}

Introduction: Novel oral anticoagulants (NOACs) have been approved for prevention of stroke and systemic embolism in patients with non-valvular atrial fibrillation (NVAF). A large number of patients are on NOACs when they present for AF ablation. We intended to evaluate the safety and efficacy of NOACs for AF ablation during the periprocedural period by

Enhanced content To view enhanced content for this article go to http://www.medengine.com/Redeem/47B 4F06014C4DF95.

Electronic supplementary material The online version of this article (doi:10.1007/s40119-016-0061-7) contains supplementary material, which is available to authorized users.

A. Vallakati · M. Madmani - W. R. Lewis Metrohealth Medical Center, Case Western Reserve University, Cleveland, OH, USA

\section{A. Sharma $(\bowtie)$}

Division of Cardiovascular Diseases, State University of New York, Downstate Medical Center, Brooklyn, NY, USA

e-mail: abhisheksharma4mamc@gmail.com

M. Reddy · A. Kanmanthareddy · S. Gunda .

D. Lakkireddy

Division of Cardiovascular Diseases, Cardiovascular

Research Institute, Mid America Cardiology,

University of Kansas Hospital and Medical Center,

Kansas City, KS, USA performing a meta-analysis of trials comparing NOACs with warfarin.

Methods: Studies comparing NOACs (dabigatran and rivaroxaban) with warfarin as periprocedural anticoagulants for AF ablation were identified using an electronic search. Primary outcomes were: (1) a composite endpoint of stroke, transient ischemic attack (TIA), peripheral arterial embolism, or silent cerebral lesions on magnetic resonance imaging (MRI) and (2) major bleeding complications. A random effects model was used to pool the safety and efficacy data across all included trials. Results: When compared to warfarin, there was an increased risk of the composite endpoint of stroke, TIA, peripheral arterial embolism, or silent cerebral lesions on MRI with NOACs as periprocedural anticoagulants for AF ablation [odds ratio (OR): 1.69, 95\% confidence interval (CI): 1.06-2.68]. Sub-group analysis revealed a higher risk of composite endpoint with dabigatran as a periprocedural anticoagulant for AF ablation (OR: 2.01, 95\% CI: 1.19-3.39) whereas the risk was similar with rivaroxaban (OR: 0.90, 95\% CI: 0.34-2.41). Sensitivity analysis after excluding silent cerebral lesions on MRI showed there was no increased risk of 
thromboembolic events with either dabigatran (OR: 1.69, 95\% CI: 0.81-3.51) or rivaroxaban (OR: 0.70, 95\% CI: 0.12-4.04). Risk of bleeding with NOACs was similar to warfarin (OR: 0.91, 95\% CI: 0.62-1.34).

Conclusion: NOACs are comparable to warfarin in terms of bleeding complications. However, dabigatran therapy is potentially associated with a higher risk of silent cerebral lesions on MRI. The results of this study should be considered as hypothesis-generating and assessed further in prospective randomized clinical studies.

Keywords: Ablation; Atrial fibrillation; Bleeding; Complications; Meta-analysis; Novel oral anticoagulants (NOACs); Thromboembolism

\section{INTRODUCTION}

Atrial fibrillation (AF) is the most common sustained cardiac arrhythmia and is associated with an increased risk of mortality, heart failure, and thromboembolic events [1-3]. Warfarin reduces the risk of stroke in moderate to high-risk AF patients [4]. Novel oral anticoagulants (NOACs) have been approved for prevention of stroke and systemic embolism in patients with non-valvular AF (NVAF) [5-8]. Prevention of AF recurrence by radiofrequency ablation (RFA) is a well accepted therapeutic strategy in patients with symptomatic AF [9]. Given the increasing use of NOACs for stroke prevention in AF over the past few years, a large number of patients are already on NOACs when they present for AF ablation [10]. Few studies reported pooled data of safety and efficacy of NOACs as periprocedural anticoagulants for $\mathrm{AF}$ ablation [11-13]. To our knowledge, there is no pooled analysis addressing the risk of cerebral microthromboembolism with these procedures.
We performed a meta-analysis of trials comparing the safety and efficacy of NOACs with warfarin in patients undergoing AF ablation.

\section{METHODS}

We conducted a systematic review of published literature comparing NOACs with warfarin for AF ablation during the periprocedural period using Meta-Analysis of Observational Studies in Epidemiology (MOOSE) guidelines [14]. We searched PubMed, the Cochrane library and Embase for studies comparing NOACs (dabigatran, apixaban, and rivaroxaban) with warfarin as periprocedural anticoagulants for RFA. The searches were extended from January 2009 to May 2014.

We used search terms "dabigatran" AND "ablation", "rivaroxaban" AND "ablation", "apixaban" AND "ablation". Meeting abstracts were searched in Embase. In the Cochrane database, search terms were limited by the term clinical trial. Limiting the search parameters to the English language was applied subsequently. Citations were screened at the title and abstract level and retrieved if they were either presented at conference or published as full reports, compared NOACs with warfarin, and provided information on the outcomes. The full texts of all potential articles were reviewed in detail. The bibliography of retained studies was used to seek additional relevant studies. All observational studies without a control group, case reports, editorials, pilot series, and reviews were excluded.

\section{Inclusion Criteria}

We included only studies that involved adult patients undergoing RFA alone and compared the outcomes with periprocedural anticoagulation with warfarin therapy (with or 
without heparin bridging) and NOACs. When two similar studies were reported from the same institution or author, the most recent publication was included in the analysis. Inclusion was not limited to prospective studies but was extended to all observational studies including retrospective studies.

\section{Exclusion Criteria}

We excluded studies if outcomes of interest were not clearly reported or were impossible to extract or calculate from the published results.

\section{Data Extraction}

Data from included studies was extracted onto a pre-formed data extraction paper by two authors (AV, MM) independently. Data was then entered into Review Manager 5.2 for analysis. Data collected included first author, year and journal of publication, study design, inclusion/exclusion criteria, definition of primary and secondary end points, number of subjects included, study population demographics, anticoagulation agent used, type of procedure, and primary outcomes. Disagreement between the reviewers was resolved by discussion.

\section{Study End Points}

Primary outcomes were:

1. A composite endpoint of stroke, transient ischemic attack (TIA), peripheral arterial embolism, or silent cerebral lesions on magnetic resonance imaging (MRI)

2. Major bleeding:

1. Bleeding requiring intervention/ hospitalization

2. Significant pericardial effusion

\section{Statistical Analysis}

We performed meta-analysis of primary outcomes using a random effects model of the Mantel-Haenszel method. Odds ratio (OR) estimates and 95\% confidence intervals (CI) were used to calculate the overall effect size of both outcomes. Statistical significance for OR was set at $P<0.05$ (two-tailed) provided the $\mathrm{CI}$ did not cross. Heterogeneity was assessed by a $\chi^{2}$ and $I^{2}$ test. Significant heterogeneity was considered present for $P$ values $<0.10$ and an $I^{2} \geq 50 \%$. Sensitivity analysis was performed by using a (1) fixed effects and random effects analysis (2) conducting a subgroup analysis (dabigatran vs. warfarin alone, rivaroxaban vs. warfarin) and (3) further subgroup analysis evaluating symptomatic thromboembolic events. Data analysis was performed using RevMan version 5.2.

\section{Compliance with Ethics Guidelines}

This article is based on previously conducted studies and does not involve any new studies of human or animal subjects performed by any of the authors.

\section{RESULTS}

Using the search key words, we identified 637 papers, of which 29 studies (dabigatran 23, rivaroxaban 6) were selected for the meta-analysis [15-41]. One study which compared NOACs with warfarin for both cardioversion and AF ablation was not included in the pooled analysis [42]. All studies included in the analysis were published between 2011 and 2014 (Fig. 1). Pooled analysis included 7671 patients, of whom 3220 (dabigatran 2629, rivaroxaban 591) were on 
NOACs and 4451 were on warfarin. The study characteristics and overall patient demographics are presented in Table 1.

\section{Composite Endpoint}

There was no significant heterogeneity among studies when assessed by $\chi^{2}$ and $I^{2}$ tests $\left(\chi^{2}=11.91 ; \quad P=0.94 ; I^{2}=0 \%\right.$; Fig. 2$)$. Pooled analysis showed that there was an increased risk of the composite endpoint of stroke, TIA, peripheral arterial embolism, or silent cerebral lesions on MRI with NOACs compared to warfarin when used for AF ablation (OR: 1.69, 95\% CI: 1.06-2.68, $P=0.03$; Fig. 3).

Subgroup analysis of studies comparing dabigatran with warfarin for $\mathrm{AF}$ ablation showed that dabigatran increased the risk of the composite endpoint (OR: 2.01, 95\% CI: 1.19-3.39, $P=0.009)$. Conversely, there was no difference in incidence of the composite endpoints between rivaroxaban and warfarin

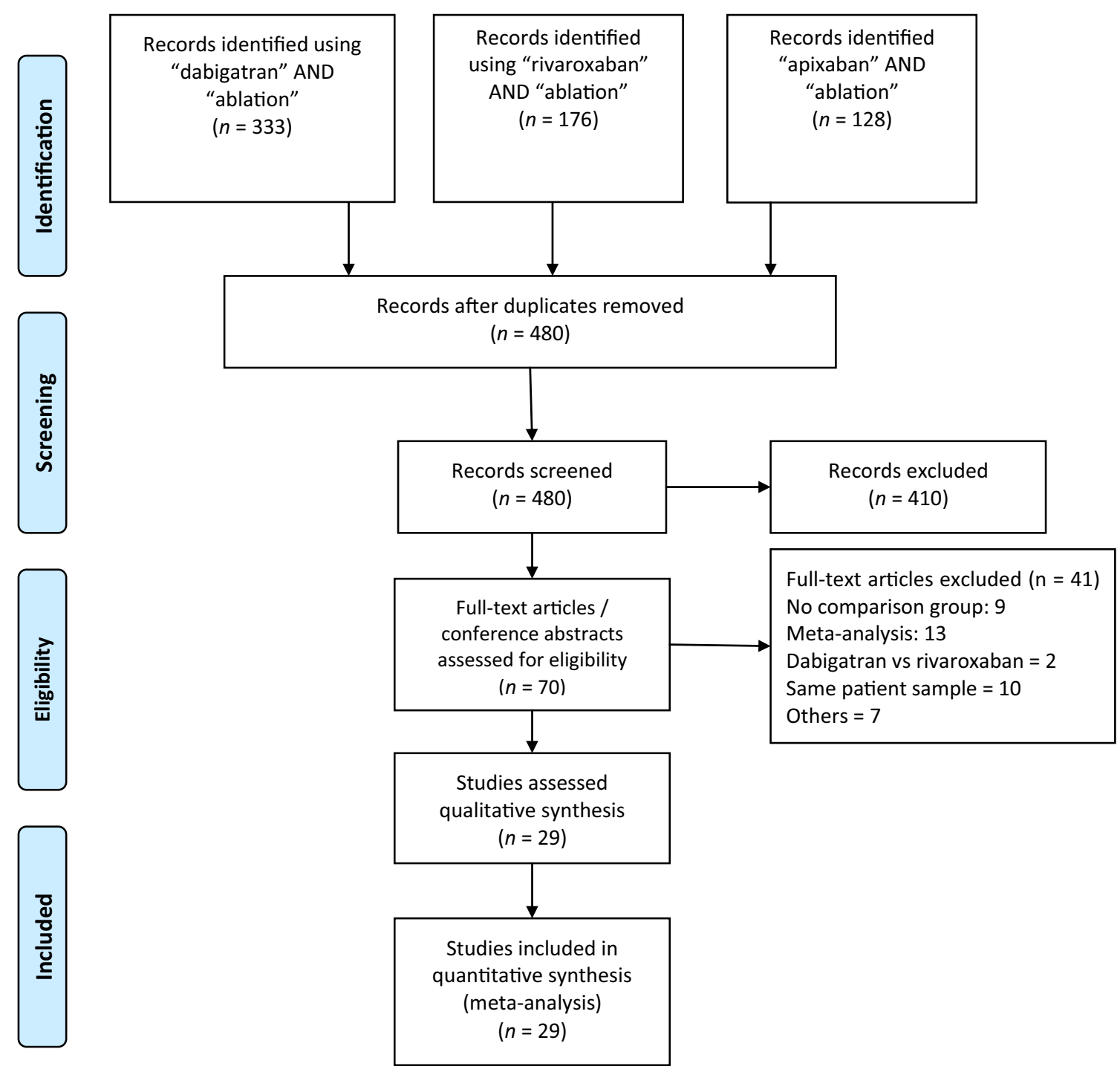

Fig. 1 Preferred reporting items for systematic reviews and meta-analyses (PRISMA) flow sheet 


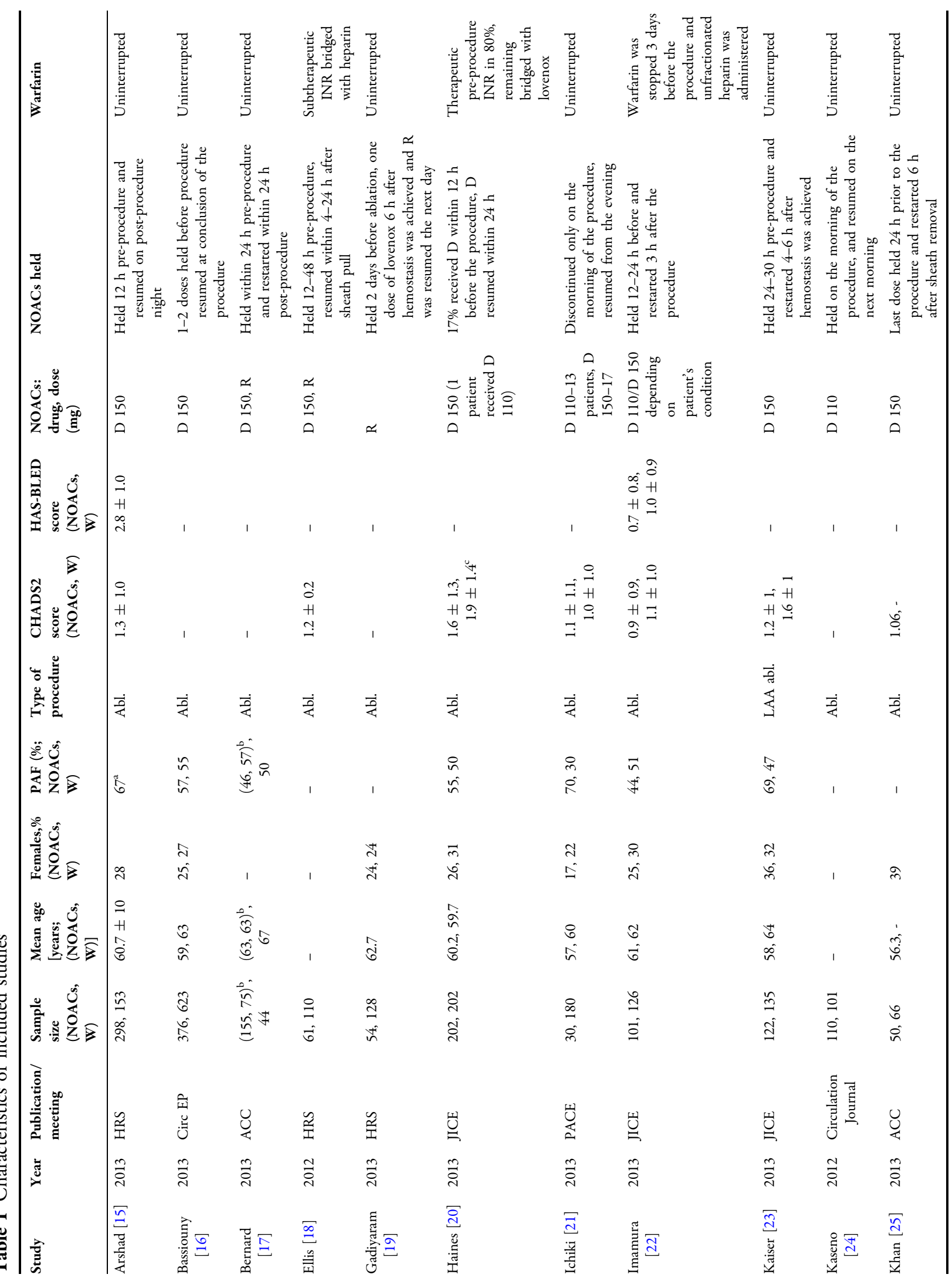




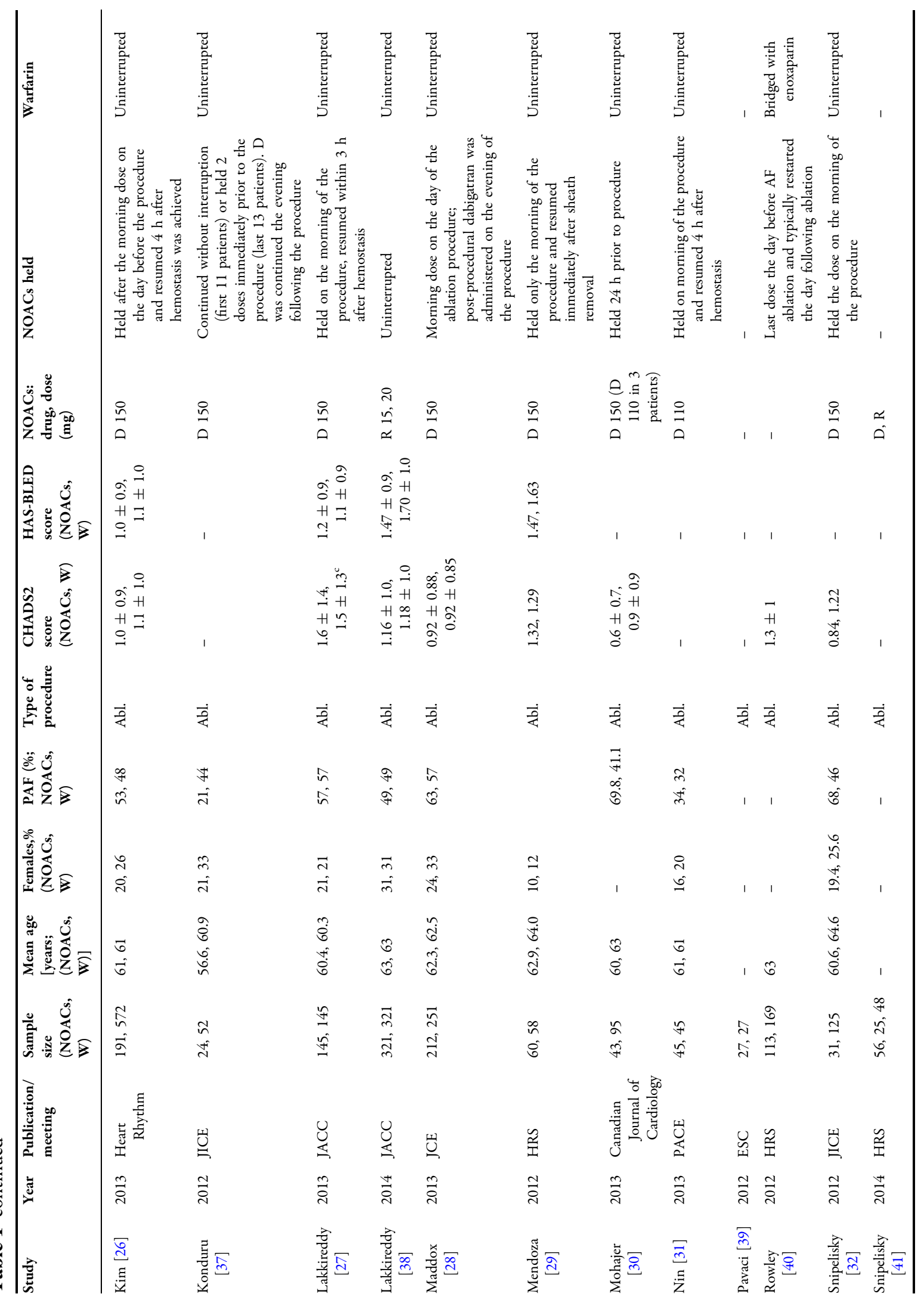




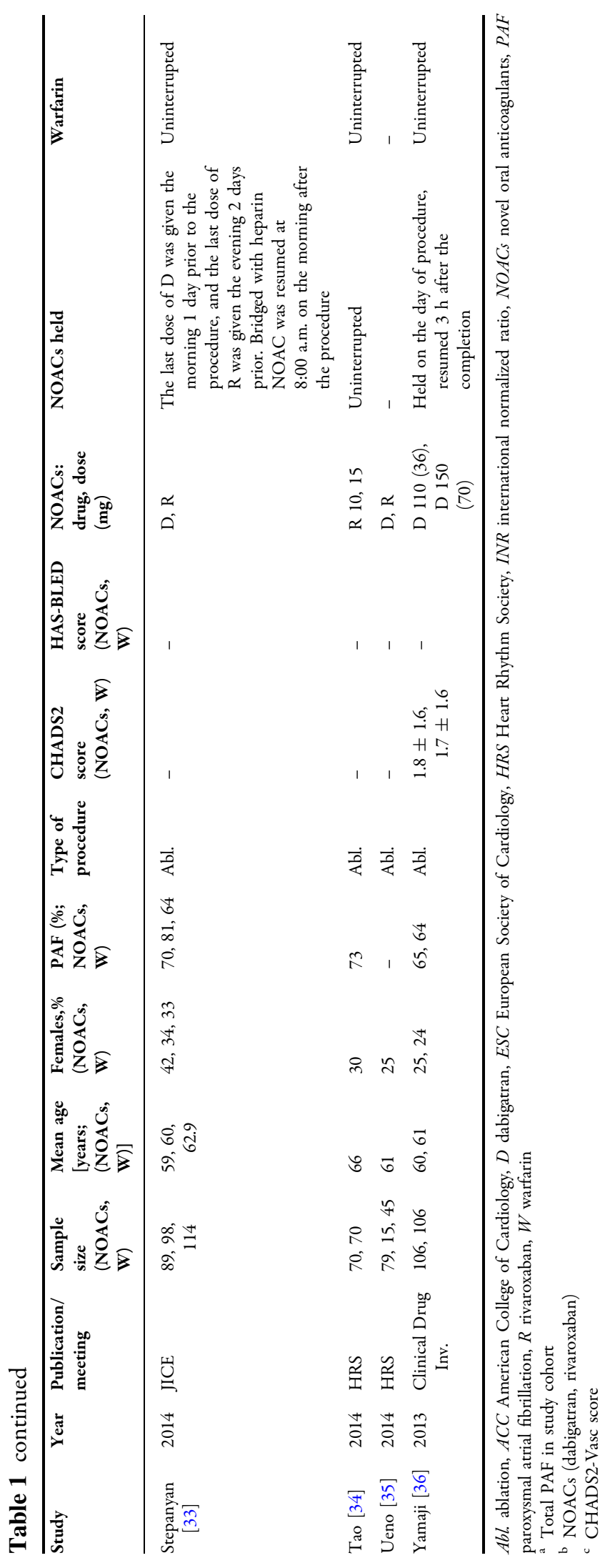




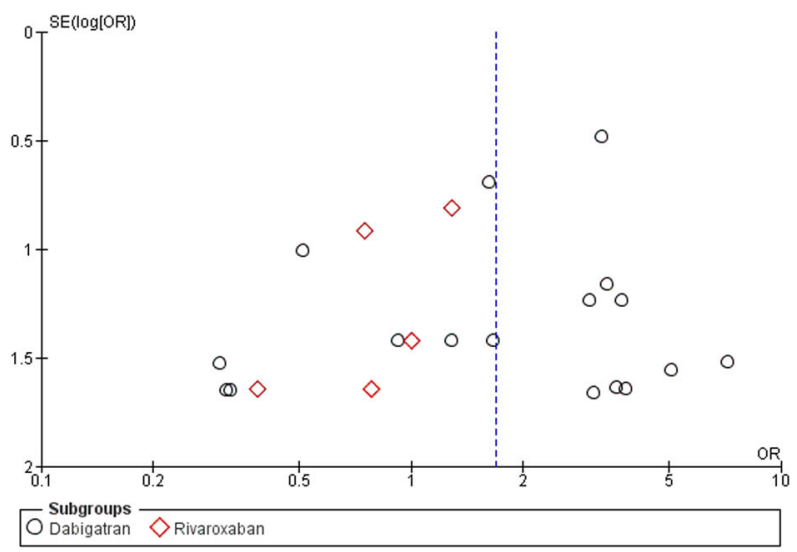

A

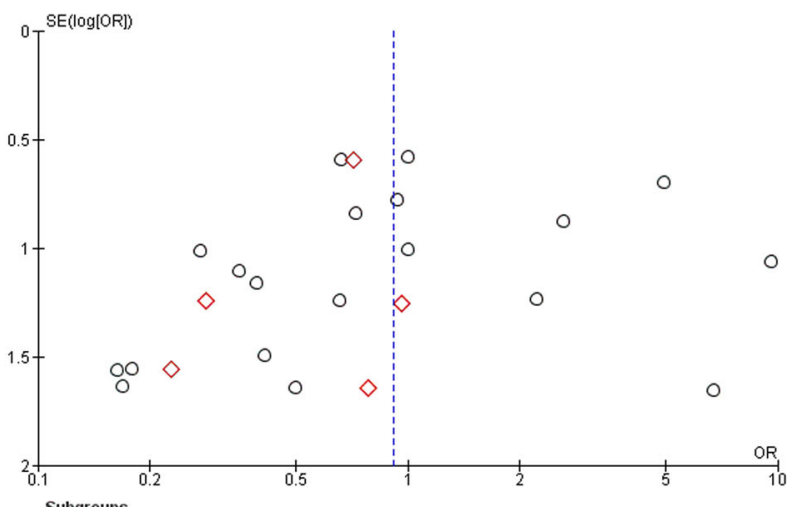

$\bigcirc$ Dabigatran $\diamond$ Rivaroxaban

B

Fig. 2 Funnel plot to assess publication bias for a the composite endpoint of stroke, TIA, peripheral arterial embolism, or silent cerebral lesions on MRI $\mathbf{b}$ major bleeding

for AF ablation (OR: 0.90, 95\% CI: 0.34-2.41, $P=0.84$ ). Sensitivity analysis was performed by using a fixed effects analysis method. Effect size did not change with fixed effects analysis.

To assess whether the time of holding NOAC affected the composite endpoint, exclusion sensitivity analysis was performed by including only those studies in which an NOAC was held on the day of AF ablation. This analysis showed that dabigatran was associated with increased risk of the composite endpoint (OR: 2.40, 95\% CI: 1.10-5.22, $P=0.03)$. On the other hand, use of rivaroxaban did not increase the risk of thromboembolic complications (OR: 1.1, 95\% CI 0.30-4.79, $P=0.79$ ).

In four studies [18, 20, 22, 40], heparin was used for bridging during the periprocedural period for anticoagulation. To assess whether uninterrupted warfarin affected the composite endpoint, sensitivity analysis was conducted by omitting studies in which heparin bridging was used. Pooled analysis of the remaining studies revealed that dabigatran was associated with increased risk of the composite endpoint (OR: 1.81, 95\% CI: 1.02-3.19, $P=0.04)$ whereas rivaroxaban therapy did not increase the risk of thromboembolic complications (OR: 0.90, 95\% CI: 0.34-2.41, $P=0.84$ ).
Exclusion sensitivity analysis including only symptomatic thromboembolic complications (stroke, TIA, and peripheral arterial embolism) was performed after omitting studies reporting silent cerebral lesions on MRI. Sensitivity analysis did not reveal any difference between NOACs and warfarin (OR: 1.48, 95\% CI: 0.75-2.91, $P=0.25$; Fig. 4). Subgroup analysis did not show any increased risk with either dabigatran or rivaroxaban for AF ablation (OR: 1.69, 95\% CI: $0.81-3.51, P=0.16$ and OR: 0.70 , 95\% CI: $0.12-4.04, \quad P=0.69, \quad$ respectively; Fig. 4).

\section{Major Bleeding}

There was no significant heterogeneity across the studies $\left(\chi^{2}=23\right.$, degrees of freedom $=23$; $\left.P=0.46 ; I^{2}=0 \%\right)$. Major bleeding events were similar with NOACs and warfarin for $\mathrm{AF}$ ablation (OR: 0.91, 95\% CI: 0.62-1.34, $P=0.63$; Fig. 5). Pooled analysis of studies in which uninterrupted warfarin was utilized for periprocedural anticoagulation did not show any significant difference in major bleeding between NOACs and warfarin (OR: 0.93, 95\% CI: 0.58-1.50, $P=0.77$ ). 


\begin{tabular}{|c|c|c|c|c|c|c|c|c|}
\hline \multirow{2}{*}{$\begin{array}{l}\text { Study or Subgroup } \\
\text { 1.3.1 Dabigatran }\end{array}$} & $\begin{array}{l}\text { NOA } \\
\text { Events }\end{array}$ & C & $\begin{array}{l}\text { warfa } \\
\text { Events }\end{array}$ & Total & Weight & $\begin{array}{l}\text { Odds Ratio } \\
\text { M-H, Random, } 95 \% \mathrm{Cl}\end{array}$ & \multicolumn{2}{|c|}{$\begin{array}{c}\text { Odds Ratio } \\
\text { M-H, Random, } 95 \% \mathrm{Cl}\end{array}$} \\
\hline & & & & & & & & \\
\hline Arshad 2013 & 2 & 298 & 2 & 153 & $5.5 \%$ & $0.51[0.07,3.66]$ & $\longleftarrow$ & \\
\hline Bassiouny 2013 & 1 & 376 & 1 & 623 & $2.8 \%$ & $1.66[0.10,26.60]$ & & \\
\hline Bernard $2013(\mathrm{D})$ & 0 & 155 & 0 & 44 & & Not estimable & & \\
\hline Ellis 2012 & 2 & 61 & 1 & 110 & $3.6 \%$ & $3.69[0.33,41.61]$ & & \\
\hline Haines 2013 & 2 & 202 & 0 & 202 & $2.3 \%$ & $5.05[0.24,105.85]$ & & \\
\hline Ichiki 2013 & 8 & 30 & 18 & 180 & $23.9 \%$ & $3.27[1.27,8.42]$ & & \\
\hline Imamura 2013 & 1 & 101 & 0 & 126 & $2.1 \%$ & $3.78[0.15,93.69]$ & & \\
\hline Kaiser 2013 & 3 & 122 & 1 & 135 & $4.1 \%$ & $3.38[0.35,32.91]$ & & \\
\hline Kaseno 2012 & 1 & 110 & 1 & 101 & $2.7 \%$ & $0.92[0.06,14.86]$ & $\longleftarrow$ & \\
\hline Khan 2013 & 0 & 50 & 0 & 66 & & Not estimable & & \\
\hline Kim 2012 & 0 & 191 & 0 & 572 & & Not estimable & & \\
\hline Konduru 2012 & 0 & 24 & 0 & 52 & & Not estimable & & \\
\hline Lakkireddy 2012 & 3 & 145 & 0 & 145 & $2.4 \%$ & $7.15[0.37,139.62]$ & & \\
\hline Maddox 2013 & 1 & 212 & 0 & 251 & $2.1 \%$ & $3.57[0.14,88.03]$ & & \\
\hline Mendoza 2012 & 0 & 60 & 1 & 58 & $2.1 \%$ & $0.32[0.01,7.94]$ & $\longleftarrow$ & \\
\hline Mohajer 2013 & 0 & 43 & 3 & 95 & $2.4 \%$ & $0.30[0.02,6.01]$ & $\longleftarrow$ & \\
\hline $\operatorname{Nin} 2013$ & 0 & 45 & 1 & 45 & $2.0 \%$ & $0.33[0.01,8.22]$ & & \\
\hline Pavaci 2012 & 1 & 27 & 0 & 27 & $2.0 \%$ & $3.11[0.12,79.87]$ & & \\
\hline Rowley 2012 & 2 & 113 & 1 & 169 & $3.7 \%$ & $3.03[0.27,33.78]$ & & \\
\hline Snipelisky 2012 & 0 & 31 & 0 & 125 & & Not estimable & & \\
\hline Stepanyan 2014 (D) & 1 & 89 & 1 & 114 & $2.7 \%$ & $1.28[0.08,20.82]$ & 4 & \\
\hline Ueno 2014 (D) & 17 & 38 & 4 & 12 & $11.5 \%$ & $1.62[0.42,6.31]$ & & \\
\hline Yamaji 2013 & 0 & 106 & 0 & 397 & & Not estimable & & \\
\hline Subtotal $(95 \% \mathrm{Cl})$ & & 2629 & & 3802 & $78.0 \%$ & $2.01[1.19,3.39]$ & & \\
\hline Total events & 45 & & 35 & & & & & \\
\hline \multicolumn{9}{|c|}{$\begin{array}{l}\text { Heterogeneity: } \mathrm{Tau}^{2}=0.00 ; \mathrm{Ch}^{2}=9.41, \mathrm{df}=16(\mathrm{P}=0.90) ; \mathrm{I}^{2}=0 \% \\
\text { Test for overall effect: } Z=2.62(P=0.009)\end{array}$} \\
\hline \multicolumn{9}{|l|}{ 1.3.2 Rivaroxaban } \\
\hline Bernard $2013(\mathrm{R})$ & 0 & 75 & 0 & 44 & & Not estimable & & \\
\hline Gadiyaram 2013 & 0 & 54 & 1 & 128 & $2.1 \%$ & $0.78[0.03,19.45]$ & $\longleftarrow$ & \\
\hline Lakkireddy 2014 & 1 & 321 & 1 & 321 & $2.8 \%$ & $1.00[0.06,16.06]$ & $\longleftarrow$ & \\
\hline Stepanyan 2014 (R) & 0 & 98 & 1 & 114 & $2.1 \%$ & $0.38[0.02,9.54]$ & $\longleftarrow$ & \\
\hline Tao 2014 & 4 & 32 & 3 & 30 & $8.5 \%$ & $1.29[0.26,6.29]$ & & \\
\hline Ueno $2014(\mathrm{R})$ & 3 & $\begin{array}{r}11 \\
591\end{array}$ & 4 & $\begin{array}{r}12 \\
649\end{array}$ & $\begin{array}{r}6.7 \% \\
22.0 \%\end{array}$ & $0.75[0.13,4.49]$ & & \\
\hline $\begin{array}{l}\text { Subtotal }(95 \% \mathrm{Cl}) \\
\text { Total events }\end{array}$ & 8 & 591 & 10 & 649 & $22.0 \%$ & $0.90[0.34,2.41]$ & & \\
\hline \multicolumn{9}{|c|}{$\begin{array}{l}\text { Heterogeneity: } \text { Tau }^{2}=0.00 ; \mathrm{Chi}^{2}=0.52, \mathrm{df}=4(\mathrm{P}=0.97) ; \mathrm{I}^{2}=0 \% \\
\text { Test for overall effect: } Z=0.21(P=0.84)\end{array}$} \\
\hline Total $(95 \% \mathrm{Cl})$ & & 3220 & & 4451 & $100.0 \%$ & $1.69[1.06,2.68]$ & & \\
\hline Total events & 53 & & 45 & & & & & \\
\hline $\begin{array}{l}\text { Heterogeneity: Tau } \\
\text { Test for overall effect } \\
\text { Test for subaroup dif }\end{array}$ & $\begin{array}{l}0.00 ; \mathrm{Chi}^{2} \\
\mathrm{z}=2.22(\mathrm{f} \\
\text { rences: }\end{array}$ & $\begin{array}{l}=11.9 \\
P=0.0 \\
C h i^{2}=1\end{array}$ & $\begin{array}{l}\text { 1, df }=21 \\
\text { 3) } \\
99, \mathrm{df}=\end{array}$ & $1(\mathrm{P}=0$ & $94) ; 1^{2}=0$ & $0 \%$ & $\begin{array}{lcl} & 1 & 1 \\
0.1 & 0.2 & 0.5 \\
\text { Favours NOACs }\end{array}$ & $1 \frac{1}{2}$ \\
\hline
\end{tabular}

Fig. 3 Forest plot showing sub group analysis of the composite endpoint of stroke, TIA, peripheral arterial embolism, or silent cerebral lesions on MRI based on type of new oral anticoagulants

\section{Major Bleeding-Type of NOACs}

Subgroup analysis, based on the type of NOAC, revealed similar major bleeding with dabigatran and warfarin when used for AF ablation (OR:
0.99, 95\% CI: $0.62-1.57, P=0.96)$. There was no significance difference in major bleeding between rivaroxaban and warfarin (OR: 0.60, 95\% CI: 0.25-1.45, $P=0.25$ ). 


\begin{tabular}{|c|c|c|c|c|c|c|c|c|}
\hline \multirow{2}{*}{$\begin{array}{l}\text { Study or Subgroup } \\
\text { 1.4.1 Dabigatran }\end{array}$} & \multicolumn{2}{|c|}{ NOAC } & \multicolumn{2}{|c|}{ warfarin } & \multirow{2}{*}{ Weight } & \multirow{2}{*}{$\begin{array}{l}\text { Odds Ratio } \\
\text { M-H, Random, } 95 \% \mathrm{Cl} \\
\end{array}$} & \multicolumn{2}{|c|}{$\begin{array}{c}\text { Odds Ratio } \\
\text { M-H, Random, } 95 \% \mathrm{Cl}\end{array}$} \\
\hline & & & & & & & & \\
\hline Arshad 2013 & 2 & 298 & 2 & 153 & $11.8 \%$ & $0.51[0.07,3.66]$ & & \\
\hline Bassiouny 2013 & 1 & 376 & 1 & 623 & $5.9 \%$ & $1.66[0.10,26.60]$ & & \\
\hline Bernard $2013(\mathrm{D})$ & 0 & 155 & 0 & 44 & & Not estimable & & \\
\hline Ellis 2012 & 2 & 61 & 1 & 110 & $7.8 \%$ & $3.69[0.33,41.61]$ & & \\
\hline Haines 2013 & 2 & 202 & 0 & 202 & $4.9 \%$ & $5.05[0.24,105.85]$ & & \\
\hline Imamura 2013 & 1 & 101 & 0 & 126 & $4.4 \%$ & $3.78[0.15,93.69]$ & & \\
\hline Kaiser 2013 & 3 & 122 & 1 & 135 & $8.8 \%$ & $3.38[0.35,32.91]$ & & \\
\hline Khan 2013 & 0 & 50 & 0 & 66 & & Not estimable & & \\
\hline Kim 2012 & 0 & 191 & 0 & 572 & & Not estimable & & \\
\hline Konduru 2012 & 0 & 24 & 0 & 52 & & Not estimable & & \\
\hline Lakkireddy 2012 & 3 & 145 & 0 & 145 & $5.2 \%$ & $7.15[0.37,139.62]$ & & \\
\hline Maddox 2013 & 1 & 212 & 0 & 251 & $4.4 \%$ & $3.57[0.14,88.03]$ & & \\
\hline Mendoza 2012 & 0 & 60 & 1 & 58 & $4.4 \%$ & $0.32[0.01,7.94]$ & & \\
\hline Mohajer 2013 & 0 & 43 & 3 & 95 & $5.1 \%$ & $0.30[0.02,6.01]$ & & \\
\hline Nin 2013 & 0 & 45 & 1 & 45 & $4.4 \%$ & $0.33[0.01,8.22]$ & & \\
\hline Pavaci 2012 & 1 & 27 & 0 & 27 & $4.3 \%$ & $3.11[0.12,79.87]$ & & \\
\hline Rowley 2012 & 2 & 113 & 1 & 169 & $7.8 \%$ & $3.03[0.27,33.78]$ & & \\
\hline Snipelisky 2012 & 0 & 31 & 0 & 125 & & Not estimable & & \\
\hline Stepanyan 2014 (D) & 1 & 89 & 1 & 114 & $5.9 \%$ & $1.28[0.08,20.82]$ & & \\
\hline $\begin{array}{l}\text { Yamaji } 2013 \\
\text { Subtotal }(95 \% \mathrm{Cl})\end{array}$ & 0 & $\begin{array}{r}106 \\
2451\end{array}$ & 0 & $\begin{array}{r}397 \\
3509\end{array}$ & $85.2 \%$ & $\begin{array}{r}\text { Not estimable } \\
1.69[0.81,3.51]\end{array}$ & & \\
\hline Total events & 19 & & 12 & & & & & \\
\hline \multicolumn{9}{|c|}{$\begin{array}{l}\text { Heterogeneity: } \mathrm{Tau}^{2}=0.00 ; \mathrm{Chi}^{2}=7.73, \mathrm{df}=13(\mathrm{P}=0.86) ; \mathrm{I}^{2}=0 \% \\
\text { Test for overall effect: } Z=1.40(\mathrm{P}=0.16)\end{array}$} \\
\hline \multicolumn{9}{|l|}{ 1.4.2 Rivaroxaban } \\
\hline Bernard $2013(R)$ & 0 & 75 & 0 & 44 & & Not estimable & & \\
\hline Gadiyaram 2013 & 0 & 54 & 1 & 128 & $4.4 \%$ & $0.78[0.03,19.45]$ & & \\
\hline Lakkireddy 2014 & 1 & 321 & 1 & 321 & $5.9 \%$ & $1.00[0.06,16.06]$ & & \\
\hline $\begin{array}{l}\text { Stepanyan } 2014(\mathrm{R}) \\
\text { Subtotal }(95 \% \mathrm{Cl})\end{array}$ & 0 & $\begin{array}{r}98 \\
548\end{array}$ & 1 & $\begin{array}{l}114 \\
607\end{array}$ & $\begin{array}{r}4.4 \% \\
14.8 \%\end{array}$ & $\begin{array}{r}0.38[0.02,9.54] \\
\mathbf{0 . 7 0}[0.12, \mathbf{4 . 0 4}]\end{array}$ & & \\
\hline Total events & 1 & & 3 & & & & & \\
\hline \multicolumn{9}{|c|}{$\begin{array}{l}\text { Heterogeneity: } \operatorname{Tau}^{2}=0.00 ; \mathrm{Chi}^{2}=0.20, \mathrm{df}=2(\mathrm{P}=0.90) ; \mathrm{I}^{2}=0 \% \\
\text { Test for overall effect: } Z=0.40(\mathrm{P}=0.69)\end{array}$} \\
\hline Total $(95 \% \mathrm{Cl})$ & & 2999 & & 4116 & $100.0 \%$ & $1.48[0.75,2.91]$ & & \\
\hline Total events & 20 & & 15 & & & & & \\
\hline $\begin{array}{l}\text { Heterogeneity: Tauz= } \\
\text { Test for overall effect: } \\
\text { Test for subqroup dif }\end{array}$ & $\begin{array}{l}0.00 ; \mathrm{Chi}^{2} \\
=1.14(\mathrm{f} \\
\text { rences: } \mathrm{C}\end{array}$ & $\begin{array}{l}=8.77 \\
P=0.25 \\
C i^{2}=0\end{array}$ & $\begin{array}{l}\text { b) } d f=16 \\
83 . d f=\end{array}$ & $(P=0.9$ & $\begin{array}{l}92) ; 1^{2}=09 \\
0.36) \cdot I^{2}=0\end{array}$ & & \begin{tabular}{cc|}
0.01 & 0.1 \\
Favours NOACs
\end{tabular} & 10 \\
\hline
\end{tabular}

Fig. 4 Forest plot showing sub group analysis of symptomatic thromboembolic events (stroke, TIA, and peripheral arterial embolism) based on type of new oral anticoagulants

\section{DISCUSSION}

There are three major findings of this study. First, the use of dabigatran for periprocedural anticoagulation for AF ablation is associated with an increased risk of the composite endpoint of stroke, TIA, peripheral arterial embolism, or silent cerebral lesions on MRI compared to warfarin. However, the risk of symptomatic thromboembolic events with dabigatran therapy is similar to anticoagulation with warfarin. Second, rivaroxaban is not associated with increased risk of the composite endpoint when compared 


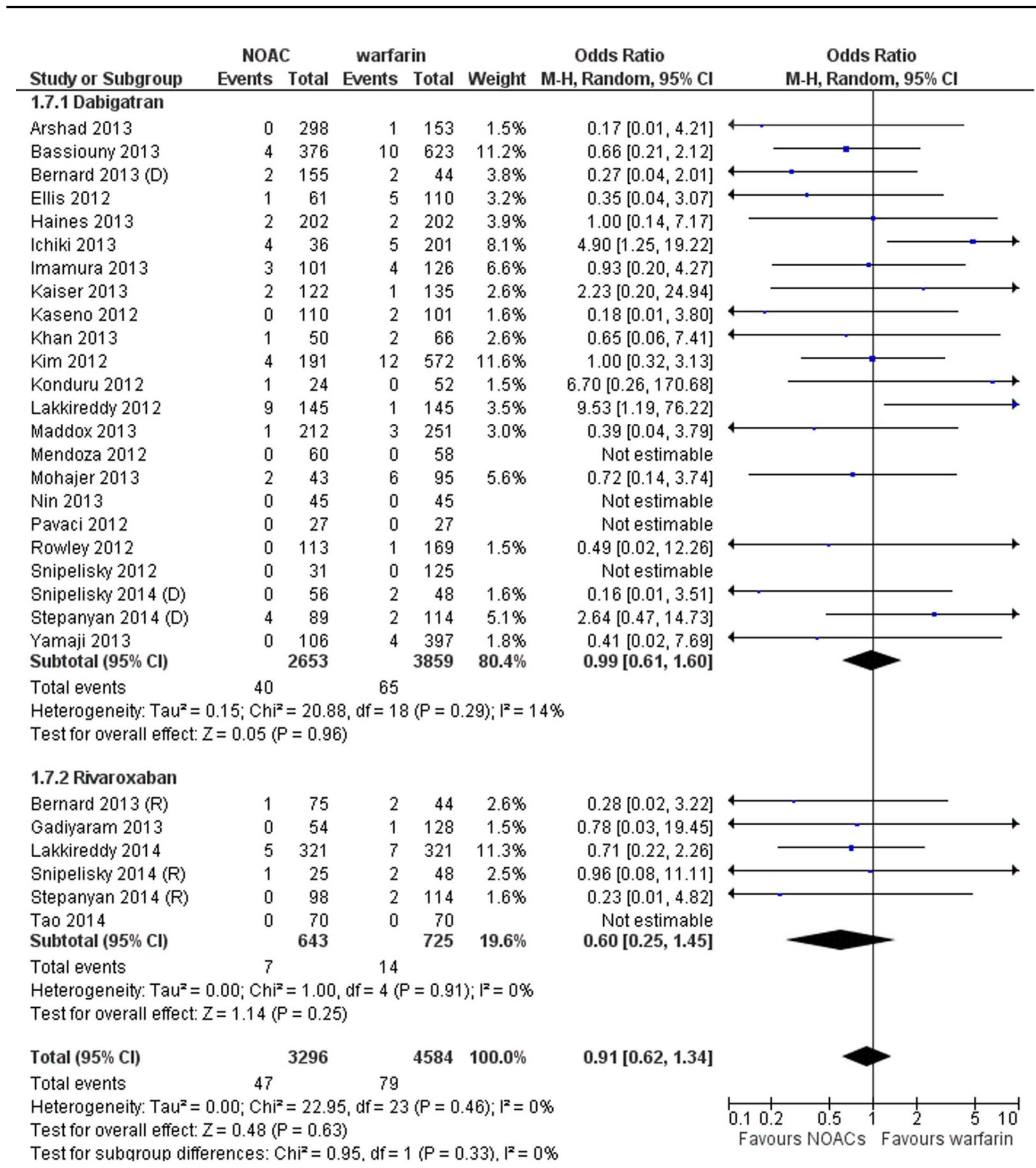

Fig. 5 Forest plot showing sub group analysis of bleeding events based on type of new oral anticoagulants

to warfarin. Third, dabigatran and rivaroxaban are comparable to warfarin in terms of bleeding complications.

Current American Heart Association (AHA)/ American College of Cardiology (ACC)/Heart
Rhythm Society (HRS) guidelines recommend anticoagulation in patients with AF with high risk for thromboembolic events identified by the CHA2DS2-VASc score [43]. Recent meta-analyses presented mixed data regarding 
the role of dabigatran therapy for periprocedural anticoagulation for AF ablation [11-13, 44]. Our study suggests dabigatran therapy for AF ablation may be associated with increased thromboembolic risk. Shurrab et al. [12] and Bin Abdulhak et al. [44] reported no significant difference in thromboembolic events between dabigatran and warfarin therapy. Sardar et al. [11] and Steinberg et al. [13] observed that periprocedural dabigatran use may be associated with increased risk of neurological events. In these meta-analyses, silent cerebral lesions on MRI were not included as one of the primary outcomes. Our study is the first pooled analysis to include and evaluate the incidence of silent cerebral lesions on MRI. Gaita et al. [45] reported an incidence of cerebral microthromboembolism of $14 \%$ with warfarin therapy for $\mathrm{AF}$ ablation and increased risk of cerebrovascular events was related to use of cardioversion. Our pooled analysis included silent cerebral lesions on MRI as one of the primary outcomes and it revealed that dabigatran therapy is potentially associated with a higher risk of silent cerebral lesions on MRI. Exclusion sensitivity analysis after omitting studies reporting silent cerebral lesions on MRI did not show any significant difference in thromboembolic events between dabigatran and warfarin therapy for $\mathrm{AF}$ ablation. Ueno et al. [46] showed that during AF ablation, pro-thrombotic factors are activated more with dabigatran than warfarin. Ichiki et al. [21] observed an increased risk of asymptomatic cerebral thromboembolic events with dabigatran therapy for AF ablation. Conversely, Kaseno et al. [24] reported similar cerebral microthromboembolism with dabigatran. Our analysis did not show any difference in the composite endpoints between rivaroxaban and warfarin therapy for $\mathrm{AF}$ ablation. This analysis may be limited by small sample size of the rivaroxaban subgroup (548 vs. 2451 in the dabigatran subgroup).

Silent cerebral infarcts may be associated with neurocognitive impairment and/or gait abnormality [47]. A recent retrospective study evaluating the incidence of silent cerebral lesions with different NOACs including edoxaban suggested an increased risk of silent cerebral lesions with dabigatran [48]. This is consistent with the findings of our study, which showed potentially higher risk of silent cerebral lesions with dabigatran. The majority (91.8\%) of the cerebral lesions noted on initial MRI were not seen on following MRI suggesting that only a few lesions develop into chronic cerebral lesions [48]. This study was limited by the retrospective and non-randomized nature of the study. Prospective randomized clinical studies are needed to evaluate the incidence of cerebral microthromboembolism with NOACs and to determine clinical characteristics which increase the likelihood of cerebral microthromboembolism.

Our study is consistent with other meta-analyses which revealed NOACs are associated with similar bleeding risk when compared to warfarin [11-13, 44]. Subgroup analysis based on type of anticoagulant did not show any difference between the NOACs.

\section{Limitations}

The studies included in the meta-analysis had differences in their study protocol. We could not study the risk of thromboembolic and bleeding events based on the dose of NOACs (110, $150 \mathrm{mg}$ of dabigatran; 10, 15, $20 \mathrm{mg}$ of rivaroxaban). There was significant heterogeneity in different protocols in terms of number of doses of NOACs held prior to the ablation, bridging therapy with heparin, and timing of resumption of NOACs after the 
procedure. Definitions for safety and efficacy outcomes, and baseline characteristics of the patients varied across the studies. The majority of the studies were observational studies without any randomization or propensity matching. Apixaban is being increasingly used in clinical practice for AF ablation. Studies evaluating the safety and efficacy of periprocedural anticoagulation with apixaban and edoxaban for AF ablation were not included in the pooled analysis [48-50] as these studies were published after the completion of the literature search in May 2014.

\section{CONCLUSIONS}

Dabigatran and rivaroxaban are comparable to warfarin in terms of bleeding complications. However, dabigatran therapy is potentially associated with a higher risk of cerebral lesions on MRI. The results of study should be considered as hypothesis-generating and assessed further in prospective randomized clinical studies.

\section{ACKNOWLEDGMENTS}

No funding or sponsorship was received for this study or publication of this article. All named authors meet the International Committee of Medical Journal Editors (ICMJE) criteria for authorship for this manuscript, take responsibility for the integrity of the work as a whole, and have given final approval for the version to be published.

Disclosures. Dhanunjaya Lakkireddy has received modest speaker's honorarium from Boehringer Ingelheim. Ajay Vallakati, Abhishek Sharma, Mohammed Madmani, Madhu Reddy, Arun Kanmanthareddy, Sampath Gunda, and
William R. Lewis have no conflict of interest relevant to the topic in discussion.

Compliance with Ethics Guidelines. This article is based on previously conducted studies and does not involve any new studies of human or animal subjects performed by any of the authors.

Open Access. This article is distributed under the terms of the Creative Commons AttributionNonCommercial 4.0 International License (http://creativecommons.org/licenses/by-nc/4. $0 /$ ), which permits any noncommercial use, distribution, and reproduction in any medium, provided you give appropriate credit to the original author(s) and the source, provide a link to the Creative Commons license, and indicate if changes were made.

\section{REFERENCES}

1. Benjamin EJ, Wolf PA, D'Agostino RB, Silbershatz $\mathrm{H}$, Kannel WB, Levy D. Impact of atrial fibrillation on the risk of death: the Framingham Heart Study. Circulation. 1998;98:946-52.

2. Go AS, Hylek EM, Phillips KA, et al. Prevalence of diagnosed atrial fibrillation in adults: national implications for rhythm management and stroke prevention: the AnTicoagulation and Risk Factors in Atrial Fibrillation (ATRIA) Study. JAMA J Am Med Assoc. 2001;285:2370-5.

3. Chugh SS, Blackshear JL, Shen WK, Hammill SC, Gersh BJ. Epidemiology and natural history of atrial fibrillation: clinical implications. J Am Coll Cardiol. 2001;37:371-8.

4. Singer DE, Chang Y, Fang MC, et al. The net clinical benefit of warfarin anticoagulation in atrial fibrillation. Ann Intern Med. 2009;151:297-305.

5. Connolly SJ, Ezekowitz MD, Yusuf S, et al. Dabigatran versus warfarin in patients with atrial fibrillation. N Engl J Med. 2009;361:1139-51.

6. Patel MR, Mahaffey KW, Garg J, et al. Rivaroxaban versus warfarin in nonvalvular atrial fibrillation. N Engl J Med. 2011;365:883-91. 
7. Granger CB, Alexander JH, McMurray JJ, et al. Apixaban versus warfarin in patients with atrial fibrillation. N Engl J Med. 2011;365:981-92.

8. Giugliano RP, Ruff CT, Braunwald E, et al. Edoxaban versus warfarin in patients with atrial fibrillation. N Engl J Med. 2013;369:2093-104.

9. Wann LS, Curtis AB, Ellenbogen KA, et al. Management of patients with atrial fibrillation (compilation of 2006 ACCF/AHA/ESC and 2011 ACCF/AHA/HRS recommendations): a report of the American College of Cardiology/American Heart Association Task Force on practice guidelines. Circulation. 2013;127:1916-26.

10. Kirley K, Qato DM, Kornfield R, Stafford RS, Alexander GC. National trends in oral anticoagulant use in the United States, 2007 to 2011. Circ Cardiovasc Qual Outcomes. 2012;5:615-21.

11. Sardar P, Nairooz R, Chatterjee S, Wetterslev J, Ghosh J, Aronow WS. Meta-analysis of risk of stroke or transient ischemic attack with dabigatran for atrial fibrillation ablation. Am J Cardiol. 2014;113:1173-7.

12. Shurrab M, Morillo CA, Schulman S, et al. Safety and efficacy of dabigatran compared with warfarin for patients undergoing radiofrequency catheter ablation of atrial fibrillation: a meta-analysis. Can J Cardiol. 2013;29:1203-10.

13. Steinberg BA, Hasselblad V, Atwater BD, et al. Dabigatran for periprocedural anticoagulation following radiofrequency ablation for atrial fibrillation: a meta-analysis of observational studies. J Interv Cardiac Electrophysiol Int J Arrhythm Pacing. 2013;37:213-21.

14. Stroup DF, Berlin JA, Morton SC, et al. Meta-analysis of observational studies in epidemiology: a proposal for reporting. Meta-analysis of Observational Studies in Epidemiology (MOOSE) group. JAMA J Am Med Assoc. 2000;283:2008-12.

15. Arshad A, Buch E, Hamam I, et al. Comparative safety of anticoagulation strategies peri-ablation for atrial fibrillation: data from a large multicenter study. Heart Rhythm. 2013;10:S74.

16. Bassiouny M, Saliba W, Rickard J, et al. Use of dabigatran for periprocedural anticoagulation in patients undergoing catheter ablation for atrial fibrillation. Circ Arrhythm Electrophysiol. 2013;6:460-4.

17. Bernard M, Brabham $\mathrm{W}$, Netzler $\mathrm{P}$, et al. Comparison of atrial fibrillation ablation bleeding and thrombotic complications with dabigatran, rivaroxaban and warfarin. J Am Coll Cardiol. 2013;61:E276.

18. Ellis CR, Streur MM, Nagarakanti R. Safety and efficacy of dabigatran versus warfarin in patients undergoing left atrial catheter ablation. Heart Rhythm. 2012;9:S421.

19. Gadiyaram VK, Boero I, Kawata H, et al. Rivaroxaban has similar safety and efficacy as warfarin for peri-procedural anticoagulation for atrial fibrillation ablation. Heart Rhythm. 2013;10:S142-3.

20. Haines DE, Mead-Salley M, Salazar $M$, et al. Dabigatran versus warfarin anticoagulation before and after catheter ablation for the treatment of atrial fibrillation. J Interv Cardiac Electrophysiol. 2013;37:233-9.

21. Ichiki H, Oketani N, Ishida S, et al. The incidence of asymptomatic cerebral microthromboembolism after atrial fibrillation ablation: comparison of warfarin and dabigatran. PACE Pacing Clin Electrophysiol. 2013;36:1328-35.

22. Imamura K, Yoshida A, Takei A, et al. Dabigatran in the peri-procedural period for radiofrequency ablation of atrial fibrillation: efficacy, safety, and impact on duration of hospital stay. J Interv Cardiac Electrophysiol. 2013;37:223-31.

23. Kaiser DW, Streur MM, Nagarakanti R, Whalen SP, Ellis CR. Continuous warfarin versus periprocedural dabigatran to reduce stroke and systemic embolism in patients undergoing catheter ablation for atrial fibrillation or left atrial flutter. J Interv Cardiac Electrophysiol. 2013;37:241-7.

24. Kaseno K, Naito S, Nakamura K, et al. Efficacy and safety of periprocedural dabigatran in patients undergoing catheter ablation of atrial fibrillation. Circ J. 2012;76:2337-42.

25. Khan S, Duggal $M$, Dunskis $P$, Bhan A. Periprocedural dabigatran in patients undergoing catheter ablation for at rial fibrillation. J Am Coll Cardiol. 2013;61:E401.

26. Kim JS, She F, Jongnarangsin K, et al. Dabigatran vs warfarin for radiofrequency catheter ablation of atrial fibrillation. Heart Rhythm. 2013;10:483-9.

27. Lakkireddy D, Reddy YM, Di Biase L, et al. Feasibility and safety of uninterrupted rivaroxaban for periprocedural anticoagulation in patients undergoing radiofrequency ablation for atrial fibrillation: results from a multicenter prospective registry. J Am Coll Cardiol. 2014;63:982-8.

28. Maddox W, Kay GN, Yamada T, et al. Dabigatran versus warfarin therapy for uninterrupted oral 
anticoagulation during atrial fibrillation ablation. J Cardiovasc Electrophysiol. 2013;24:861-5.

29. Mendoza I, Helguera M, Baez-Escudero J, Reina J, Pinski SL. Atrial fibrillation ablation on uninterrupted anticoagulation with dabigatran versus warfarin. Heart Rhythm. 2012;9:S270-1.

30. Mohajer K, Haley C, Simpson C, et al. Comparison of dabigatran and conventional anticoagulation practices in patients undergoing elective left atrial ablation. Can J Cardiol. 2013;29:S184.

31. Nin T, Sairaku A, Yoshida Y, et al. A randomized controlled trial of dabigatran versus warfarin for periablation anticoagulation in patients undergoing ablation of atrial fibrillation. PACE Pacing Clin Electrophysiol. 2013;36:172-9.

32. Snipelisky D, Ray J, Ung R, Duart M, Kauffman C, Kusumoto F. A comparison of bleeding complications between warfarin and dabigatran in patients undergoing cryoablation. Heart Rhythm. 2014;11:S456-7.

33. Stepanyan G, Badhwar N, Lee RJ, et al. Safety of new oral anticoagulants for patients undergoing atrial fibrillation ablation. J Interv Cardiac Electrophysiol. 2014;40:33-8.

34. Tao S, Kenichiro O, Yuichi O, et al. Efficacy and safety of rivaroxaban versus warfarin as uninterrupted anticoagulation for radiofrequency catheter ablation of atrial fibrillation. Heart Rhythm. 2014;11:S228.

35. Ueno A, Morita N, Iida T, Fujibayashi D, Kobayashi Y. Evaluation of peri-procedural coagulation status of atrial fibrillation ablation; impact of different anticoagulants on the risk of silent cerebral infarction. Heart Rhythm. 2014;11:S395.

36. Yamaji H, Murakami T, Hina K, et al. Usefulness of dabigatran etexilate as periprocedural anticoagulation therapy for atrial fibrillation ablation. Clin Drug Investig. 2013;33:409-18.

37. Konduru SV, Cheema AA, Jones P, Li Y, Ramza B, Wimmer AP. Differences in intraprocedural ACTs with standardized heparin dosing during catheter ablation for atrial fibrillation in patients treated with dabigatran vs. patients on uninterrupted warfarin. J Interv Cardiac Electrophysiol. 2012;35:277-84.

38. Lakkireddy D, Reddy YM, Di Biase L, et al. Feasibility and safety of dabigatran versus warfarin for periprocedural anticoagulation in patients undergoing radiofrequency ablation for atrial fibrillation: results from a multicenter prospective registry. J Am Coll Cardiol. 2012;59:1168-74.
39. Pavaci H, Reents T, Ammar S, et al. Safety and efficacy of dabigatran in patients undergoing left atrial ablation procedures: a case matched analysis. Eur Heart J. 2012;33:60-1.

40. Rowley CP, Bradford NS, Bernard ML, et al. Complications of atrial fibrillation ablation in patients anticoagulated with dabigatran compared to warfarin. Heart Rhythm. 2012;9:S201.

41. Snipelisky D, Kauffman C, Kusumoto F. A comparison of bleeding complications post ablation between warfarin and dabigatran. Heart Rhythm. 2012;9:S203.

42. Piccini JP, Stevens SR, Lokhnygina Y, et al. Outcomes after cardioversion and atrial fibrillation ablation in patients treated with rivaroxaban and warfarin in the ROCKET AF Trial. J Am Coll Cardiol. 2013;61:1998-2006.

43. Anderson JL, Halperin JL, Albert NM, et al. Management of patients with atrial fibrillation (compilation of 2006 ACCF/AHA/ESC and 2011 ACCF/AHA/HRS recommendations): a report of the American College of Cardiology/American Heart Association Task Force on Practice Guidelines. J Am Coll Cardiol. 2013;61:1935-44.

44. Bin Abdulhak AA, Khan AR, Tleyjeh IM, et al. Safety and efficacy of interrupted dabigatran for peri-procedural anticoagulation in catheter ablation of atrial fibrillation: a systematic review and meta-analysis. Europace Eur Pacing Arrhythm Cardiac Electrophysiol J Work Groups Cardiac Pacing Arrhythm Cardiac Cell Electrophysiol Eur Soc Cardiol. 2013;15:1412-20.

45. Gaita F, Caponi D, Pianelli M, et al. Radiofrequency catheter ablation of atrial fibrillation: a cause of silent thromboembolism? Magnetic resonance imaging assessment of cerebral thromboembolism in patients undergoing ablation of atrial fibrillation. Circulation. 2010;122:1667-73.

46. Ueno A, Morita N, Iida T, Fujibayashi D, Kobayashi Y. Comparison of coagulation status using dabigatran with warfarin for periprocedural anticoagulation during atrial fibrillation ablation procedure. Heart Rhythm. 2013;10:S384.

47. Fanning JP, Wesley AJ, Wong AA, Fraser JF. Emerging spectra of silent brain infarction. Stroke J Cereb Circ 2014;45:3461-3471.

48. Nakamura K, Naito S, Sasaki T, et al. Silent cerebral ischemic lesions after catheter ablation of atrial fibrillation in patients on 5 types of periprocedural oral anticoagulation-predictors of diffusion-weighted imaging-positive lesions and follow-up magnetic resonance imaging. Circ J Off J Jpn Circ Soc. 2016;80:870-7. 
49. Di Biase L, Lakkireddy D, Trivedi C, et al. Feasibility and safety of uninterrupted periprocedural apixaban administration in patients undergoing radiofrequency catheter ablation for atrial fibrillation: results from a multicenter study. Heart Rhythm Off J Heart Rhythm Soc. 2015;12:1162-8.
50. Rillig A, Lin T, Plesman J, et al. Apixaban, rivaroxaban, and dabigatran in patients undergoing atrial fibrillation ablation. J Cardiovasc Electrophysiol. 2016;27:147-53. 